\title{
Human Face Recognition, Information Processing and Social Behavior in Children with Autism
}

\author{
Pascale Planche \\ UFR Lettres et Sciences Humaines, Université de Bretagne Occidentale, Brest, France \\ Email: pascale.planche@univ-brest.fr
}

Received 5 June 2014; revised 3 July 2014; accepted 1 August 2014

Copyright (C) 2014 by author and Scientific Research Publishing Inc. This work is licensed under the Creative Commons Attribution International License (CC BY). http://creativecommons.org/licenses/by/4.0/ (c) (7) Open Access

\begin{abstract}
The aim of this study was to investigate whether children with high-functioning autism (HFA) and Asperger's syndrome (AS) can be differentiated from each other and from typically developing children in ability to recognize a human face. The present study included 69 participants: children with autism (high-functioning autism or Asperger's syndrome, $\mathbf{n}=15$ per group) and a control group of 39 typically developing children. It involved a face recognition task included in the NEPSY scale. Results showed that the autism groups performed poorer than the typically developing group, but no difference was found between high-functioning and Asperger groups. Both the information processing peculiarities of children with autism and their (interactional and communicative) social impairments could explain their difficulty to recognize human faces.
\end{abstract}

\section{Keywords}

Asperger's Syndrome, High-Functioning Autism, Face Recognition, Information Processing, Social Impairment

\section{Introduction}

Autism Spectrum Disorders (ASDs) includes a range of neurodevelopmental disorders: autism, Asperger's syndrome, and pervasive developmental disorders that are characterized by qualitative impairment of social interactions, verbal and non-verbal communication deficiencies, and restricted and repetitive interests (American Psychiatric Association, 1994). Within this spectrum, Asperger's syndrome (AS) differs from high-functioning autism (HFA) by a lack of significant delay in language or cognitive development (Tantam, 1988). Clinical criteria to distinguish between high-functioning autism (HFA) and Asperger's syndrome (AS) were established through 
the publication of ICD-10 (World Health Organization, 1993) and DSM-IV (APA, 1994). Asperger's syndrome has been mainly characterized by a lack of significant delay in language or cognitive development, but with autistic social impairment, pragmatic difficulties, and patterns of restricted, repetitive and stereotyped behaviors, interests and activities. Ritvo et al. (2008) suggested that these criteria were given with the expectation that ongoing research would provide indications permitting to determine whether there are two distinct disorders, or a single one with different degrees of severity. To date, the results are contradictory, no consensus has been reached about a separation of participants with AS from ones with HFA (see Tsai, 2013, for a review) even though both disorders were combined into a single category of autism spectrum disorder in DSM-5 (APA, 2013). The present study will contribute to this current debate.

People with autism have major problems in the register of social interactions and they tend to avoid the gaze of their interlocutor in an exchange. Communication by gaze is the primary form of communication used by humans. In children, face processing skills are significantly correlated with measures of attention to faces and with social skills (Parish-Morris, Chevallier et al., 2013).

A large number of studies in children with ASD have investigated face perception, face recognition, or faceexpressivity recognition, sometimes in association with other social features such as identity, age, gender, and face familiarity (Baron-Cohen, Campbell, Karmiloff-Smith et al., 1995; Dawson, Webb, Wijsman et al., 2005; Deruelle, Rondan, Gepner, \& Tardiff, 2004; Klin, Sparrow, de Bildt, Cicchetti et al., 1999; McPartland, Dawson, Webb et al., 2004; Schultz, Gauthier, Klin et al., 2000...). All of them reported abnormalities in these abilities for individuals with autism compared to typically developing individuals.

One of the first investigations on face recognition, in subjects with ASD, was conducted by Langdell (1978) and it tested the ability of children with autism to recognize isolated facial features of known peers from photographs of only their face. In contrast to typical children of the same age, children with autism were better able to recognize photographs of their peers when were shown the lower half of the face rather than the upper half. They tended to focus their attention on the mouth area. The author suggested that typically developing subjects are able to extract more knowledge from the eye area because they frequently use this region as an important source of information about the inner state of another person, whereas children with autism have a tendency to extract visual cues from the mouth area in spoken communications.

In a study on gaze direction, in which participants watched videotape clips of social scenes, using eye tracking technology to capture spontaneous viewing patterns of subjects with autism compared to those of control subjects, Klin et al. (2002) confirmed the previous findings. It appeared that individuals with autism focused 2 times more on the mouth region, 2 times less on the eye region, 2 times more on the body region and 2 times more on the object region relative to the control group. These results suggested the authors that eyes may not be meaningful for individuals with autism, whereas the mouth is meaningful because this is the region where speech comes from. Furthermore, according to them, their "participants were not only focusing on the verbal content of speech but were also ignoring paralinguistic cues such as prosody which are usually essential to understanding nonliteral aspects of social situations” (Klin et al., 2002: p. 814).

More recent studies agree with these initial findings and have procured more specific data on face perception in individuals with autism (Chevallier, Grèzes et al., 2012; Dawson et al., 2005; Deruelle et al., 2004; Hadjikhani et al., 2004; McPartland, Dawson, Webb, Panagiotides, \& Carver, 2004; Rice, Moriuchi et al., 2012; Tanaka, Wolf, Klaiman et al., 2012; Valla, Maendel, Ganzel et al., 2013).

To summarize all of these results, when individuals with autism were looking at or trying to recognize faces, they displayed a preference for local information processing of faces rather than configural processing. This means that individuals with autism focus on local details (isolated facial features) constituting the face rather than on the global configuration. These observations agree with the theoretical model proposed by Frith (1989) who evoked a "lack of central coherence" in individuals with autism, or more precisely, with the idea of the priority granted to the treatment of local information (Happé, 1999; Mottron, Burack, Iarocci et al., 2003; Planche \& Lemonnier, 2011).

However, this argument is insufficient to explain the observations. Indeed, if subjects took into account only the characters' eyes in a task of face recognition, this would also be the expression of a piecemeal perceptual style. Furthermore, in order to recognize faces successfully, it is necessary to consider not only all of the features, but also their perceptual-spatial organization. The ability to recognize faces requires complex visuospatial processing insofar as the elements to identify and memorize are arranged on the facial surface and located in relation to one other by spatial markers, such as the relationship of symmetry that characterizes eye position, the centre 
position of the nose, and the mouth below. Children with ASD seem to have difficulties with this exercise that involves a configural processing of the face features.

But, it has been reported that other visuospatial tasks are not impaired in individuals with autism. For example, the pattern of scores on tasks of the Wechsler scale that require visuospatial processing ("picture completion", "object assembly" and "block design"), and the global assessment of visuospatial functions measured by the NEPSY scale, showed no significant difference between children with high-functioning autism and typically developing children of the same age (Planche \& Lemonnier, 2011, 2012). Most often, children with autism succeeded with the only use of analytical treatments (locating details and topographic clues) which were sufficient to guide step-by-step the structuration of the space and achieve a success rate comparable to that of typically developing subjects who have mobilized a global processing without difficulty when it was required by the task. Therefore, among children with autism, when global processing is difficult or impossible, then recourse may be made to local processing to compensate for the lack of global treatment (Planche et al., 2002; van Boxtel \& Lu, 2013). Why does this seem impossible in face recognition? Perhaps, it is because information processing by details co-occurs with impairments in social reciprocity that people with autism focus more on the lower part of the face and avoid the gaze, as suggested by Valla et al. (2013).

The objective of the present study was to gain a better understanding of the type of specific processing required for face recognition in children with autism.

To this aim, the "recognition of two target faces" subtest was used. It has been proposed, among others, by the NEPSY Scale (2003) ${ }^{1}$ to assess visual attention. This subtest has an original design and requires various cognitive functions and complex information processing. We believe it could be used to refine our knowledge on the treatment of information contained in human faces by individuals with autism. Moreover, the results of the present study may lead to a better understanding of the impairments of communication and interactional skills of this population. They could also contribute to the current debate on the validity of the distinction between AS and HFA.

\section{Method}

\subsection{Participants}

This study included a total of 69 children who were distributed into three groups (Table 1) matched on age and global level of intelligence as follows: children with high-functioning autism (HFA), children with Asperger's syndrome (AS) and typically developing children (control group). The Wechsler scale was used to evaluate cognitive level for the subjects of the clinical groups.

15 children with HFA, (14 boys and 1 girl), were recruited from the Regional Autism Centre of Brittany in the Unit of Child and Adolescent Psychiatry, at the University Hospital of Brest, France. All of them have been assessed by one psychiatrist; they all met the required criteria for autism according to ICD-10 (F84.0) confirmed by ADI-R (Lord, Rutter, \& Le Couteur, 1994) and also had a full scale IQ above 70. At the time of the study, they used a functional language (scored 0 at item 19 of ADI-R). However, all of them initially presented a marked delay in language. This feature differentiated them from children with Asperger's syndrome. This group had a mean chronological age of 8 years 6 months (range: 6 years and 2 months to 10 years and 7 months).

Table 1. Descriptive characteristics of participants in HFA, AS and control groups.

\begin{tabular}{cccc}
\hline & & Groups & \\
\cline { 2 - 4 } & HFA & AS & Control \\
\hline $\mathrm{N}$ & 15 & 15 & 39 \\
Mean age & 8.06 & 8.03 & 7.06 \\
Range & $6.02-10.07$ & $6.01-9.10$ & \\
Mean FIQ-WISC-III & 98.07 & 105.53 & \\
(S.D.) & $(26.16)$ & $(16.87)$ & \\
\hline
\end{tabular}

\footnotetext{
${ }^{1}$ As this subtest has been removed from the latest version of this scale, we preferred to use the 2003 scale rather than one published in 2012.
} 
15 children with AS, (13 boys and 2 girls), were recruited as previously. All of them have been assessed by one psychiatrist and have received a diagnosis of AS. These subjects met the required criteria for autism according to ICD-10 (F84.5) confirmed by ADI-R. They had no history of language delay and a normal language development, i.e. ability to use single words by the age of 2 and to make communicative phrases by the age of 3 . They also had a full scale IQ above 70. The mean chronological age of this group was 8 years 3 months (range: 6 years and 1 month to 9 years and 10 months).

Control group: 39 typically developing children (22 boys and 17 girls) were recruited from local, mainstream schools. These children followed the school curriculum with neither delay nor advance. None of them had a known history of neurological or psychiatric disorders or developmental retardation. None of their first-degree family members had a pervasive developmental disorder. The mean chronological age of this group was 8 years and 6 months (range: 7 years and 9 months to 9 years and 7 months).

All participants had normal, or corrected-to-normal vision.

There was no significant difference in the chronological age $[\mathrm{F}(2,66)=0.2919, p=0.747]$ between the three groups, (HFA, AS and typically developing groups).

Student $t$-tests indicated no significant difference between clinical groups (HFA and AS groups) in Full Scale IQ $(t=1.23 ; p=0.11 ; \mathrm{ddl}=28)$.

Informed and written consents were obtained from their parents.

\subsection{Instruments}

The Wechsler Intelligence Scale for Children-Third Edition (WISC III), designed for children between the ages of 6 years 0 months and 16 years 11 months, enabled an assessment of the IQ scores of the clinical groups. Changes in the composition of the latest version of this task drove us to prefer the WISC-III rather than the WISC-IV, which was published in 2005, and thus already available at the time of data collection for this study. Indeed, the "object assembly" and "picture arrangement" tasks have both been removed in WISC-IV and "picture completion" is now optional. All these tasks require the mobilization of visuo-spatial functions. This study involves a task that requires the processing of visuospatial information, consequently the WISC-III seemed better suited to assess the overall level of our clinical groups.

The subtest "recognition of two target faces" included in the visual attention tasks of the NEPSY scale enabled an evaluation and comparison of the capacity of each group (clinical and control) to recognize two different faces among a set. The NEPSY assessment (a Developmental Neuropsychological Assessment by Korkman, Kirk, \& Kemp, French Adaptation, 2003) consists of 14 core subtests designed to assess 5 neuropsychological domains: Executive, Language, Sensorimotor, Visuospatial and Memory. Their psychometric properties are satisfactory.

In this task, the subject must recognize two faces among 96 drawn on a sheet of A3 paper and presented in rows and columns (Figure 1). First, he/she must identify and memorize the characteristic features of these two drawn target faces ("models") in order to then recognize them among all of the other faces presented on the paper. The features of a human face-eyes, nose, mouth, eyebrows, hairstyle-are shown in various combinations to produce 12 different faces, each one of which is replicated eight times and randomly dispersed throughout the protocol. In a limited time period of 180 seconds, the subject must recognize 20 faces similar to the two targets among the 96 shown on the protocol. During the task, the subject may refer to the target faces at any time.

From task execution, it is possible to calculate the number of identified targets, missed targets and falsealarms (faces designated by the subject but which do not correspond to the targets).

The tests were individually administered to the participants in a quiet room. All testing with the clinical groups was conducted by the same psychologist (P.P.).

\section{Results}

Results can be visualized in Table 2. First, no significant difference was found between the three groups regarding time taken to solve the task (limited to 180 seconds): [F $(2,66)=0.1761, p=0.838]$.

No significant difference was found between the three groups on the mean score of correct targets identified $[\mathrm{F}(2,66)=2.044, p=0.137]$. No significant difference was found between HFA and AS groups for this score $(p=0.06)$.

No significant difference was identified between the clinical groups and the typically developing group on the 


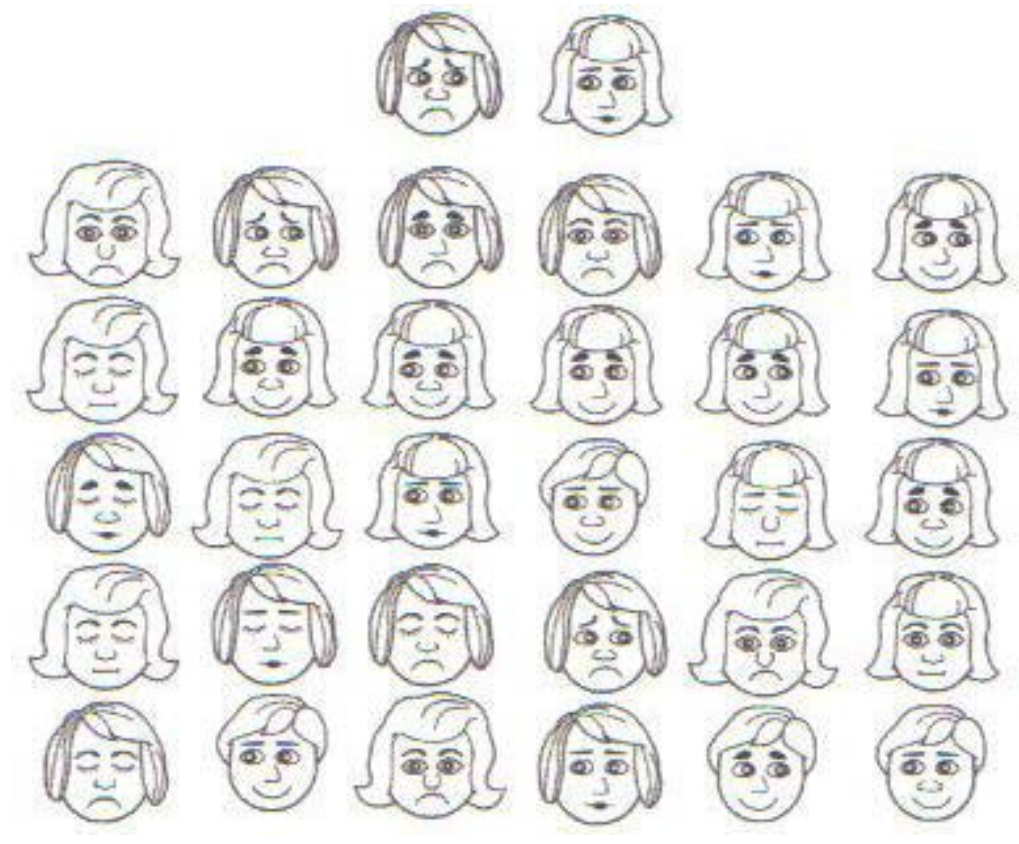

Figure 1. An excerpt of the "recognition of two target faces" task.

Table 2. Mean scores (standard deviation) for the face recognition task in each population.

\begin{tabular}{|c|c|c|c|c|}
\hline & \multicolumn{3}{|c|}{ Groups } & \multirow{2}{*}{$p$ value $(\mathrm{F})^{\mathrm{a}}$} \\
\hline & HFA & AS & Normal Dev. & \\
\hline Number of correct targets identified & $16.13(3.72)$ & $13.87(3.94)$ & $15.56(2.8)$ & \\
\hline Number of missed targets & $3.87(3.7)$ & $6.13(3.9)$ & $4.44(2.8)$ & \\
\hline Number of false alarms & $2.07(2.01)$ & $2.61(2.4)$ & $0.33(0.6)$ & $p<0.000$ \\
\hline
\end{tabular}

${ }^{\mathrm{a}}$ Significant differences appear in bold type: $[\mathrm{F}(2,66)=11.474, p<0.000]$.

mean score of missed targets $[\mathrm{F}(2,66)=2.044, p=0.137]$. No significant difference was found between HFA and AS groups for this score $(p=0.07)$.

The mean score of false alarms appeared to be significantly higher in AS and in HFA groups than for subjects in the typically developing group, $t=3.58, p=0.001$ and $t=2.44, p=0.013$, respectively. However, no significant difference was found between HFA and AS groups for this score $(p=0.253)$. In terms of frequency, 12/15 (80\%) subjects with AS and HFA produced false alarms (designation of faces that did not correspond to the targets) against 10/39 (25.5\%) of typically developing children.

\section{Discussion}

The main objective of this study was to gain a better understanding of the information processing involved in face recognition among children with autism, in particular because this exercise appears to be particularly difficult for them, and it could induce interactional and communicational impairments.

Another study objective was to try to characterize the specific cognitive functioning of children with AS and children with HFA for this skill in order to question whether or not these disorders are distinct.

The autism groups and the typically developing group did not significantly differ on the mean score of correct targets identified and of missed targets, but a significant difference was identified on the false-alarm score. Furthermore, on the whole task, no difference was found between AS and HFA subjects.

Children with autism obtained poorer results on this task than the control group in an equivalent period of time. Indeed, there was no significant difference between autistic and typically developing groups regarding number of faces identified, but children with autism ticked more faces and produced more false alarms (i.e. 
faces that did not match the targets) than typically developing children. The face recognition procedure among individuals with autism is less effective and this is probably because i) their mode of information capture is different than that of typically developing children, ii) the large number of faces to run through on the sheet when searching for the target faces imposes a too heavy cognitive load, and iii) this task has a social component which may disturb people with autism.

This face recognition task involves the processing of visuospatial information. People with autism are "well known" for their preserved visuospatial skills, but this task involves the implementation of a complex perceptual-cognitive treatment that is perhaps more complex than that required for the visuospatial tasks classically used for the assessment of people with autism. The various steps in the task solving process require different modes of successive processing. Two images (the target faces) must be seized as a whole and then dismantled. After a first step that consists in understanding the organization of each face proposed as a model, the subject must break down the complex structures into pieces to memorize the details in order to be able to recognize them afterwards. Therefore, global processing is first required, then analytic treatment is needed to identify, locate and memorize all of the characteristics of the two target faces. Both the holistic representation of the target faces and their individual features seem to be relevant to their recognition (see Piepers \& Robbins, 2012, for a review). Individuals with autism have difficulties because they use atypical strategies focusing first on isolated facial features rather than on the overall configuration, whereas, in the typically developing population the global aspect of faces is processed before the details constituting the face (Deruelle, Rondan, Gepner et al., 2004).

For solving the face recognition task of the present study, cognitive load is important because of the high number of stimuli to be simultaneously considered. Then, it is necessary to take into account all of the drawings, one line after another, "carrying over" the characteristics of the models into the pictorial representation in order to recognize them among all of the faces presented on the sheet. Consequently, this target faces recognition task requires the processing, storage and recall of numerous stimuli, and an ordered visual scan of the space of the sheet of paper to be effective and not to miss a face that is similar to both targets. Therefore, it uses a great deal of working memory and selective visual attention. Although people with autism usually use analytical and sequential information processing in their environmental interactions, when the number of stimuli to deal with exceeds a certain threshold, sequential processing is disrupted (Planche et al., 2002). Their processing capacities are limited to a small number of stimuli to be effective. In our task, all of the stimuli to deal with could overflow their processing system and could lead to a dysfunction.

Analysis of the errors in ticking faces made by the autism (HFA and AS) groups and the typically developing group showed that children with autism probably memorized more mouth than eye characteristics on the two models $(72.34 \%$ of the errors in pointing false targets were eye-related in children with AS, $64.5 \%$ in children with HFA, while the mouth was a weak source of error). According to findings from previous studies, we assume that children with autism focused their attention more on the lower part of the face, when they were considering the facial features, whereas typically developing children have probably stored the facial features as a whole and consequently their choices were more precise and they produced fewer errors in recognizing target faces among all of the faces presented on the sheet. One limitation of our study is to have not used the eye tracking technology to record visual fixations on faces, this could have been particularly useful in order to fully assess this hypothesis.

Moreover, this task used graphical representations of human faces so it is not significantly neutral like the other visuospatial tasks used to assess children with autism (e.g. the "block design”, "picture completion" tasks of the Wechsler scale). In real life, people with autism avoid the gaze of their interlocutor as it is overloaded with stimuli: probably, all of these stimuli could overflow their processing system (emotional and cognitive) and destabilize them. The eyes are rarely motionless and individuals with autism are also characterized by hypersensitivity to rapid sensory flows that generate a disorder in the perception of both physical environmental and human facial or body movements (Gepner, 2005). Thus, the peculiarities of their mode of information processing with reduced visual attention to the face and low social motivation for engaging in social contact, could explain their poor face recognition skills (Chevalier, Grèzes et al., 2012; Chevallier, Kohls et al., 2012; Parish-Morris, Chevallier, Tonge et al., 2013). The present study showed that in an experimental context, children with autism reproduced on the face drawings the behavior that they implement in an ecological situation. Therefore, these children seem to treat information as they do in real life: with a tendency to avoid the gaze. Kenworthy et al. (2008) suggested that in some areas, children with autism generally perform better in tasks conducted in a labo- 
ratory setting than in a more natural one. However, our findings for this task did not agree with this proposition, probably because of the robustness of this attitude and consequently, their (interactional and communicative) difficulties in social register.

Our findings did not allow to introduce a differentiation between HFA and AS children on this task. Possible explanations for these results might be that i) both HFA and AS groups do not differ on local and global information processing (Rinehart, Bradshaw, Moss, Brereton, \& Tonge, 2000; Planche \& Lemonnier, 2012; Spek, Scholte, \& Van Berckelaer-Onnes, 2011), and have both an inability to process verbal and non-verbal communications adequately, ii) both groups display an insufficient ability to read the complex meanings expressed through the gaze of others; thus they tend to avoid the gaze of their interlocutor in a exchange and they have strong difficulties in the registers of social interactions.

\section{Conclusion}

To conclude, the present study suggests that both the specific information processing of children with autism and their (interactional and communicative) social impairments could explain their difficulty to recognize human faces in tasks conducted in an experimental situation, as well as in establishing eye contact with others in interpersonal exchanges in a more natural setting.

Consequently, educational interventions like social remediation through particular skills training, theater exercises, both starting at the earliest possible age and focusing on abilities underlining social interactions (capacities to establish eye contact when communicating, to discern and understand social signal conveyed by expressions of faces), and on pragmatic conversational abilities (the comprehension of humour, of irony, of metaphoric utterances), may all in all be beneficial to children with autism in order to improve their socialisation and their adaptation to everyday life.

\section{Acknowledgements}

We are grateful to Hugo Leroy (Psychology student) who carried out the data collection in the mainstream schools. We would also like to thank the children and their parents of the Regional Autism Centre of Brittany in the Unit of Child and Adolescent Psychiatry, at the University Hospital of Brest, France, along with the schools who participated in this research.

\section{References}

American Psychiatric Association (2013). Diagnostic and Statistical Manual of Mental Disorders (5th ed.). Washington DC: American Psychiatric Association.

American Psychiatric Association (1994). Diagnostic and Statistical Manual of Mental Disorders (4th ed.). Washington DC: American Psychiatric Association.

Baron-Cohen, S., Campbell, R., Karmiloff-Smith, A., Grant, J., \& Walker, J. (1995). Are Children with Autism Blind to the Mentalistic Significance of the Eyes? British Journal of Developmental Psychology, 13, 379-398. http://dx.doi.org/10.1111/j.2044-835X.1995.tb00687.x

Chevallier, C., Grèzes, J., Molesworth, C., Berthoz, S., \& Happé, F. (2012). Selective Social Anhedonia in High Functioning Autism. Journal of Autism and Developmental Disorders, 42, 1504-1509. http://dx.doi.org/10.1007/s10803-011-1364-0

Chevallier, C., Kohls, G., Troiani, V., Brodkin, E. S., \& Schultz, R. T. (2012). The Social Motivation Theory of Autism. Trends in Cognitive Science, 16, 231-239. http://dx.doi.org/10.1016/j.tics.2012.02.007

Dawson, G., Webb, S. J., Wijsman, E. S. G., Estes, A., Munson, J., \& Faja, S. (2005). Neurocognitive and Electrophysiological Evidence of Altered Face Processing of Children with Autism: Implications for a Model of Abnormal Development of Social Brain Circuitry in Autism. Development and Psychopathology, 17, 679-697. http://dx.doi.org/10.1017/S0954579405050327

Deruelle, C., Rondan, C., Gepner, B., \& Tardiff, C. (2004). Spatial Frequency and Face Processing in Children with Autism and Asperger Syndrome. Journal of Autism and Developmental Disorders, 34, 199-209.

http://dx.doi.org/10.1023/B:JADD.0000022610.09668.4c

Frith, F. U. (1989). Autism Explaining the Enigma. Cambridge: Basil Blackwell.

Gepner, B. (2005). Malvoyance du mouvement dans l'autisme: De la clinique à la recherche et à la rééducation. In C. Andrés, C. Barthélémy, A. Berthoz, J. Massion, \& B. Rogé (Eds.), L’autisme : De la recherche à la pratique (pp. 205-226). Paris: Odile Jacob. 
Hadjikhani, N., Joseph, R. M., Snyder, J., Chabris, C. F., Clark, J., Steele, S. et al. (2004). Activation of the Fusiform Gyrus When Individuals with Autism Spectrum Disorder View Faces. Neuroimage, 22, 1141-1150.

http://dx.doi.org/10.1016/j.neuroimage.2004.03.025

Happé, F. (1999). Autism: Cognitive Deficit or Cognitive Style? Trends in Cognitive Science, 3, 216-222. http://dx.doi.org/10.1016/S1364-6613(99)01318-2

Kenworthy, L., Yerys, B. E., Anthony, L. G., \& Wallace, G. L. (2008). Understanding Executive Control in Autism Spectrum Disorders in the Lab and in the Real World. Neuropsychological Review, 18, 320-338. http://dx.doi.org/10.1007/s11065-008-9077-7

Klin, A., Jones, W., Schultz, R., Volkmar, F., \& Cohen, D. (2002). Visual Fixation Patterns during Viewing of Naturalistic Social Situations as Predictors of Social Competence in Individuals with Autism. Archives of General psychiatry, 59, 809816. http://dx.doi.org/10.1001/archpsyc.59.9.809

Klin, A., Sparrow, S. S., de Bildt, A., Cicchetti, D. V., Cohen, D. J., \& Volkmar, F. R. (1999). A Normed Study of Face Recognition in Autism and Related Disorders. Journal of Autism and Developmental Disorders, 29, 499-508. http://dx.doi.org/10.1023/A:1022299920240

Korkman, M., Kirk, U., \& Kemp, S. (2003). NEPSY, bilan neuropsychologique de l'enfant. ECPA: Editions du Centre de Psychologie Appliquée.

Langdell, T. (1978). Recognition of Faces: An Approach to the Study of Autism. Journal of Child Psychology and Psychiatry, 19, 255-268. http://dx.doi.org/10.1111/j.1469-7610.1978.tb00468.x

Lord, C., Rutter, M., \& Le Couteur, A. (1994). Autism Diagnostic Interview-Revised: A Revised Version of a Diagnostic Interview for Caregivers of Individuals with Possible Pervasive Developmental Disorders. Journal of Autism and Developmental Disorders, 24, 659-685. http://dx.doi.org/10.1007/BF02172145

McPartland, J., Dawson, G., Webb, S. J., Panagiotides, H., \& Carver, L. J. (2004). Event Related Brain Potentials Reveal Anomalies in Temporal Processing of Faces in Autism Spectrum Disorder. Journal of Child Psychology and Psychiatry and Allied Disciplines, 45, 1235-1245. http://dx.doi.org/10.1111/j.1469-7610.2004.00318.x

Mottron, L., Burack J. A., Iarocci, G., Belleville, S., \& Enns, J. T. (2003). Locally Oriented Perception with Intact Global Processing among Adolescents with High-Functioning Autism: Evidence from Multiple Paradigms. Journal of Child Psychology and Psychiatry, 44, 904-913. http://dx.doi.org/10.1111/1469-7610.00174

Parish-Morris, J., Chevallier, C., Tong, N., Letzen, J., Pandey, J., \& Schultz, R. T. (2013). Visual Attention to Dynamic Faces and Objects Is Linked to Face Processing Skills: A Combined Study of Children with Autism and Controls. Frontiers in Psychology, 4, 185. http://dx.doi.org/10.3389/fpsyg.2013.00185

Piepers, D. W., \& Robbins, R. A. (2012). A Review and Clarification of the Terms “Holistic,” "Configural,” and "Relational” in the Face Perception Literature. Frontiers in Psychology, 3, 559. http://dx.doi.org/10.3389/fpsyg.2012.00559

Planche, P., \& Lemonnier, E. (2011). Le pic d’habileté aux tâches visuospatiales chez les autistes de haut niveau désigne-t-il vraiment un déficit du traitement global? L'Encéphale, 37, 10-17. http://dx.doi.org/10.1016/j.encep.2010.03.007

Planche, P., \& Lemonnier, E. (2012). Children with High-Functioning Autism and Asperger's Syndrome: Can We Differentiate Their Cognitive Profiles? Research in Autism Spectrum Disorders, 6, 939-948. http://dx.doi.org/10.1016/j.rasd.2011.12.009

Planche, P., Lemonnier, E., Moalic, K., Labous, C., \& Lazartigues, A. (2002). Les modalités du traitement de l'information chez les enfants autistes. Annales Médico-Psychologiques, 160, 559-564.

http://dx.doi.org/10.1016/S0003-4487(02)00231-7

Rice, K., Moriuchi, J. M., Jones, W., \& Klin, A. (2012). Parsing Heterogeneity in Autism Spectrum Disorders: Visual Scanning of Dynamic Social Scenes in School-Aged Children. Journal of the American Academy of Child and Adolescent Psychiatry, 51, 238-248. http://dx.doi.org/10.1016/j.jaac.2011.12.017

Rinehart, N. J., Bradshaw, J. L., Moss, S. A., Brereton, A. V., \& Tonge, B. J. (2000). Atypical Interference of Local Detail on Global Processing in High-Functioning Autism and Asperger's Disorder. Journal of Child Psychology and Psychiatry, 41, 769-778. http://dx.doi.org/10.1111/1469-7610.00664

Ritvo, R. A., Ritvo, E. R., Guthrie, D., \& Ritvo, M. J. (2008). Clinical Evidence That Asperger's Disorder Is a Mild Form of Autism. Comprehensive Psychology, 49, 1-5. http://dx.doi.org/10.1016/j.comppsych.2007.06.010

Schultz, R., Gauthier, I., Klin, A., Fulbright, R. K., Anderson, A. W., Volkmar, F., Skudlarski, P., Lacadin, C., Cohen, D. J., \& Gore, J. C. (2000). Abnormal Ventral Temporal Cortical Activity during Face Discrimination among Individuals with Autism and Asperger Syndrome. Archives of General Psychiatry, 37, 331-340. http://dx.doi.org/10.1001/archpsyc.57.4.331

Spek, A. A., Scholte, E. M., \& Van Berckelaer-Onnes, I. A. (2011). Local Information Processing in Adults with High Functioning Autism and Asperger Syndrome: The Usefulness of Neuropsychological Tests and Self-Reports. Journal of Autism and Developmental Disorders, 41, 859-869. http://dx.doi.org/10.1007/s10803-010-1106-8 
Tanaka, J. W., Wolf, J. M., Klaiman, C., Koenig, K., Cockburn, J., Herlihy, L. et al. (2012). The Perception and Identification of Facial Motions in Individuals with Autism Spectrum Disorders Using the Let's Face It! Emotion Skills Battery. Journal of Child Psychology and Psychiatry, 53, 1259-1267. http://dx.doi.org/10.1111/j.1469-7610.2012.02571.x

Tantam, D. (1988). Asperger's Syndrome. Journal of Child Psychology and Psychiatry, 29, 245-255. http://dx.doi.org/10.1111/j.1469-7610.1988.tb00713.x

Tsai, L. Y. (2013) Asperger’s Disorder Will Be Back. Journal of Autism and Developmental Disorders, 43, $2914-2942$. http://dx.doi.org/10.1007/s10803-013-1839-2

Valla, J. M., Maendel, J. W., Ganzel, B. L., Barsky, A. R., \& Belmonte, M. K. (2013). Autistic Trait Interactions Underlie Sex-Dependant Facial Recognition Abilities in the Normal Population. Frontiers in Psychology, 4, 286. http://dx.doi.org/10.3389/fpsyg.2013.00286

Van Boxtel, J. J., \& Lu, H. (2013). Impaired Global, and Compensatory Local, Biological Motion Processing in People with High Levels of Autistic Traits. Frontiers in Psychology, 4, 209. http://dx.doi.org/10.3389/fpsyg.2013.00209 
Scientific Research Publishing (SCIRP) is one of the largest Open Access journal publishers. It is currently publishing more than 200 open access, online, peer-reviewed journals covering a wide range of academic disciplines. SCIRP serves the worldwide academic communities and contributes to the progress and application of science with its publication.

Other selected journals from SCIRP are listed as below. Submit your manuscript to us via either submit@scirp.org or Online Submission Portal.
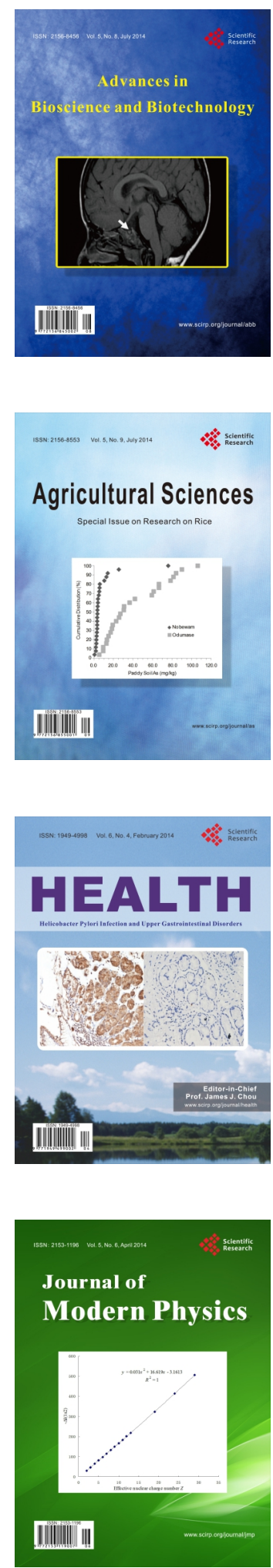
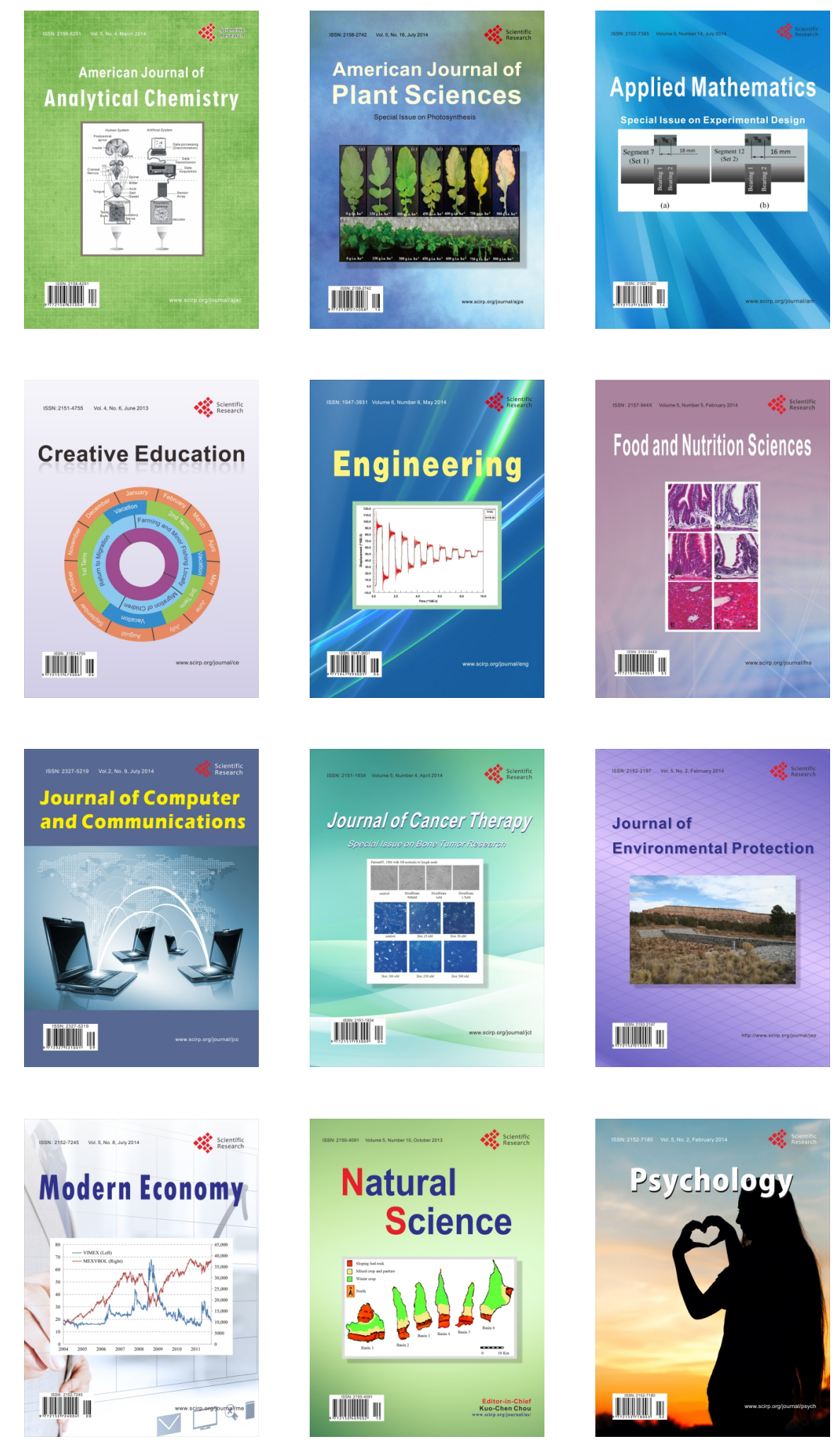